\title{
Trifunctional (Pyropheophorbide $a$ - Steroid - Hexadecyl Chain) Conjugates: Synthesis, Solubilization, Interaction with Cultured Cells
}

\author{
Maria O. Taratynova, ${ }^{a}$ Vladimir A. Zolottsev, ${ }^{a}$ Yaroslav V. Tkachev, $^{\mathrm{b}}$ \\ Roman A. Novikov, ${ }^{b}$ Maria G. Zavialova, ${ }^{a}$ Galina E. Morozevich, ${ }^{a}$ \\ Vladimir P. Timofeev, ${ }^{\mathrm{b}}$ Yulia V. Romanenko, ${ }^{\mathrm{c}}$ Oskar I. Koifman, ${ }^{\mathrm{c}}$ \\ Alexander Y. Misharin, ${ }^{\mathrm{a}}$ and Gelii V. Ponomarev ${ }^{\mathrm{a}}$ \\ ${ }^{a}$ Orekhovich Institute of Biomedical Chemistry, 119121 Moscow, Russia \\ ${ }^{\mathrm{b}}$ Engelhardt Institute of Molecular Biology RAS, 119991 Moscow, Russia \\ ${ }^{\mathrm{C}}$ Research Institute of Macroheterocycles, Ivanovo State University of Chemistry and Technology, 153000 Ivanovo, Russia \\ ${ }^{\circledR}$ Corresponding authorE-mail: gelii@yandex.ru
}

\begin{abstract}
Two novel complex conjugates (containing three functional units: pyropheophorbide a, 17 $\alpha$-substituted testosterone, and lipophylic hexadecyl chain, connected with L-lysine joining block) were synthesized. The scheme consisted of condensation of $N(\alpha)$-Fmoc- $N(\varepsilon)$-Boc-Lys with hexadecyl amine, followed by consecutive removal of $N$-protective groups and coupling of obtained intermediates either with pyropheophorbide a, or with 17 $\beta$-hydroxy-3-oxopregn-4-en-21-oic acid. Mutual influence of steroidal and macrocyclic fragments depending on conjugate structure was established by analysis of NMR spectra and molecular models of conjugates. Complex conjugates easily formed mixed micelles with phosphatidyl choline and pluronic F68; these mixed micelles efficiently internalized by human hepatocarcinoma Hep G2 cells, and slightly - by human prostate carcinoma LNCaP cells. The binding of complex conjugates to cells was dependent on the conjugate structure.
\end{abstract}

Keywords: Pyropheophorbide a, testosterone derivatives, conjugates, chemical synthesis, molecular models, phospholipid micelles, Hep G2 and LNCaP cells.

\section{Трифункциональные (пирофеофорбид $a$ - стероид - гексадецильная цепь) конъюгаты: синтез, солюбилизация, взаимодействие с клетками в культуре}

\author{
М. О. Таратынова, ${ }^{a}$ В. А. Золотцев, ${ }^{a}$ Я. В. Ткачев, ${ }^{\text {b }}$ Р. А. Новиков, ${ }^{b}$ \\ М. Г. Завьялова, ${ }^{a}$ Г. Е. Морозевич, ${ }^{a}$ В. П. Тимофеев, ${ }^{\mathrm{b}}$ Ю. В. Романенко, ${ }^{\mathrm{c}}$ \\ О. И. Койфрман, ${ }^{\text {c }}$ А. Ю. Мишарин, ${ }^{a}{ }^{\text {Г }}$. В. Пономарев ${ }^{a}$
}

\begin{abstract}
а'Институт биомедицинской химии им. В.Н. Ореховича, 119121 Москва, Россия
' Институт молекулярной биологии им. В.А. Энгельгардта РАН, 119991 Москва, Россия

'НИИ химии макрогетероциклических соединений, Ивановский государственный химико-технологический университет, 153000 Иваново, Россия

@E-mail: gelii@yandex.ru
\end{abstract}

\begin{abstract}
Синтезированы два новых комплексных конъюгата, содержащих три функциональных остатка: пиро-

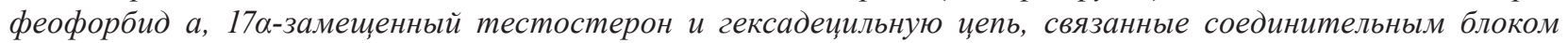
на основе L-лизина. Схема включала конденсачию $N(\alpha)$-Fmoc-N(E)-Boc-Lys с гексадециламином, последовательное удаление $N$-защиттных групп и конденсацию полученных продуктов либо с пирофеофорбидом а, либо с 17ß-гидрокси-3-оксопрегн-4-ен-21-овой кислотой. Анализ спектров ЯМР и молекулярных моделей конъюгатов показал, что взаимное влияние стероидного и макрочиклического фрагментов зависит от структуры
\end{abstract}


конъюгата. Сложные конъюгаты образовывали смешанные мицелль с фосфатидилхолином и плюроником F68; эти смешанные мицелль эффективно интернализовались клетками гепатокарииномы человека НерG2 и слабо - клетками карииномы предстательной железы человека LNCaP, причем интернализация зависела от структуры конъюгата.

Ключевые слова: Пирофеофорбид $a$, производные тестестерона, конъюгаты, химический синтез, молекулярные модели, фосфолипидные мицеллы, Hep G2 и LNCaP клетки.

\section{Introduction}

Tetrapyrrolic macrocycles such as chlorins and porphyrins owing to their unique photochemical and photophysical properties are widely used in biomedical investigations as agents for optical imaging and fluorescent labeling, as well as in practical medicine as sensitizers for photodynamic therapy of solid tumors. Conjugation of macrocycles with polyamines, amino acids, peptides, sugars, steroids, oxysterols, bile acids, fragments of drugs, etc. ${ }^{[1-10]}$ is the prospective approach to improve their specific targeting and delivery, accumulation in tumor tissues, biological and photodynamic properties. Incorporation of macrocycle containing conjugates in liposomes, dendrimer-like nanoparticles, reconstructed low density lipoproteins, phospholipid vesicles and micelles increased solubility of conjugates in aqueous medium, and facilitated their transport through receptor or drug mediated endocytosis..$^{[1-15]}$

In our previous studies we have synthesized and studied bivalent conjugates of chlorins and pyropheophorbide $a$ with cholesterol, some steroids, and lipophylic hydrocarbon fragments. ${ }^{[13-17]}$ It was found that testosterone-pyropheophorbide $a$ conjugate exhibited antiproliferative activity and photo induced cytotoxicity in prostate carcinoma cells, ${ }^{[17]}$ while $17^{3}$ (hexadecylcarbamoyl)-pyropheophorbide $a$ simply solubilized in aqueous medium as mixed micelles with phospholipids. ${ }^{[15]}$ These findings inspire our wish to develop new type of conjugates, in which macrocycle, targeting group, and lipophylic moiety (responsible for solubilization in form mixed micelles) would be joined in one molecule.

The goal of the present study is synthesis and primary evaluation of new complex conjugates $\mathbf{1}$ and $\mathbf{2}$ (Figure 1). The molecule of each conjugate contains three aforementioned functional units, connected by means of L-lysine joining block. In isomeric conjugates $\mathbf{1}$ and $\mathbf{2}$ the relative positions of pyropheophorbide $a$ and steroid units are the same, however these units are located differently in relation to hexadecyl chain.

We investigated spectral properties and molecular models of conjugates $\mathbf{1}$ and $\mathbf{2}$, examined their ability to form mixed micelles with phosphatidyl choline, and compared uptake and internalization of conjugates $\mathbf{1}$ and $\mathbf{2}$ (solubilized as mixed micelles either with phosphatidyl choline, or with pluronic F68) by cultured carcinoma cells. The data presented herein revealed that mixed micelles: conjugate-phosphatidyl choline may possess significant pharmacological potency, since they efficiently accumulated in tumor cells.

\section{Experimental}

\section{General}

HRMS were registered on a Bruker 'Apex Ultra' FT ICR MS instrument at ion positive electro spray ionization mode; ${ }^{1} \mathrm{H}$ NMR and ${ }^{13} \mathrm{C}$ NMR spectra - on an AMX-III instrument (Bruker, $400 \mathrm{MHz}$ ) in $\mathrm{CDCl}_{3}$ (the values for ${ }^{1} \mathrm{H}$ in $\mathrm{CHCl}_{3}$ was $7.28 \mathrm{ppm}$ and ${ }^{13} \mathrm{C}$ in $\mathrm{CDCl}_{3}$ was $77.16 \mathrm{ppm}$; assignment of proton resonances was performed using the set of 2D NMR spectra); absorption spectra - on a "Cary Spectra 100 " spectrophotometer in $\mathrm{CHCl}_{3}$ using a quartz cell with a $1 \mathrm{~mm}$ optical path length. Particle size distribution was measured with "DelsaNano Beckman Coulter" instrument.

\section{Chemical Synthesis}

Pyropheophorbide $a \mathbf{3}$ and 17ß-hydroxy-3-oxopregn-4en-21-oic acid 4 were synthesized as described earlier, ${ }^{[17]} N(\alpha)$ Fmoc-N(E)-Boc-Lys 5 and hexadecyl amine $\mathbf{6}$ were purchased from "Acros", other reagents and solvents were purchased from "Aldrich", "Merck", “Acros", "Fluka", and "Spectra Chem,
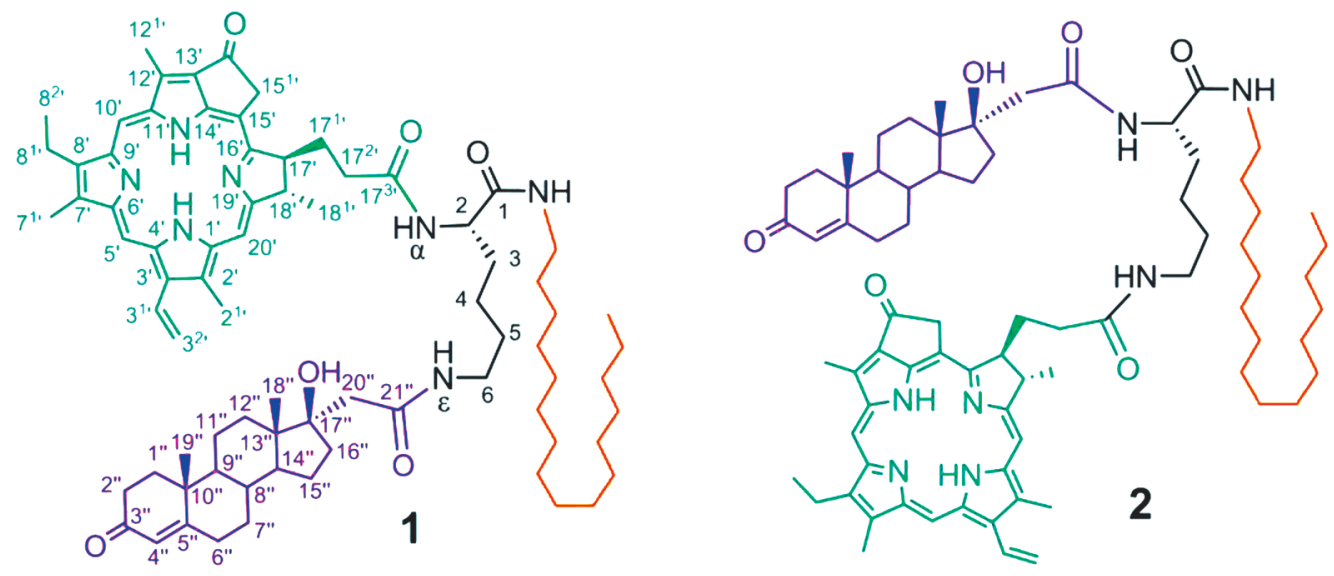

Figure 1. Structure of conjugates synthesized and investigated in the present study. 
(Moscow, Russia)". Flash chromatography was performed on $(0.035-0.070 \mathrm{~mm})$ silica gel from "Acros", TLC - on Silica gel UV-254 HPTLC plates from 'Merck'.

$N(\alpha)$-Fmoc-N(E)-Boc-Lys-hexadecyl amide 7. $N(\alpha)$ Fmoc-N(ع)-Boc-Lys 5 (200 mg, $0.427 \mathrm{mmol}$ ) and DCC (97 mg, $0.47 \mathrm{mmol})$ were dissolved in dry $\mathrm{CH}_{2} \mathrm{Cl}_{2}(12 \mathrm{~mL})$, then hexadecyl amine 6 (103 $\mathrm{mg}, 0.427 \mathrm{mmol}$ ) was added, the mixture was stirred, the reaction being controlled by TLC. After $1 \mathrm{~h}$ the mixture was diluted with $\mathrm{CH}_{2} \mathrm{Cl}_{2}$, washed with $\mathrm{NaHCO}_{3}$ saturated solution $(20 \mathrm{~mL})$, water $(20 \mathrm{~mL})$, brine $(20 \mathrm{~mL})$, dried over $\mathrm{Na}_{2} \mathrm{SO}_{4}$ and evaporated to obtain amide $7(257 \mathrm{mg}, 0.371 \mathrm{mmol}, 87 \%)$ as white solid. HRMS, calculated for $\mathrm{C}_{42} \mathrm{H}_{66} \mathrm{~N}_{3} \mathrm{O}_{5}^{+}: 692.4997$, found: 692.4988. ' $\mathrm{H}$ NMR $\delta_{\mathrm{H}}$ ppm: $0.87\left(3 \mathrm{H}, \mathrm{t} J=6.7 \mathrm{~Hz}, \mathrm{CH}_{3}\right.$-hexadecyl), $1.24\left(28 \mathrm{H}, \mathrm{m}, \mathrm{CH}_{2}\left(\mathrm{CH}_{2}\right)_{14} \mathrm{CH}_{3}\right), 1.42\left(9 \mathrm{H}, \mathrm{s}, \mathrm{CH}_{3}-\mathrm{Boc}\right), 3.09(2 \mathrm{H}, \mathrm{q}$ $J=5.8 \mathrm{~Hz}, \mathrm{NCH}_{2}(\varepsilon)$-Lys), $3.21\left(2 \mathrm{H}, \mathrm{q} J=5.4 \mathrm{~Hz}, \mathrm{NCH}_{2}\right.$-hexadecyl), 4.07 (1H, m, CH( $\alpha$ )-Lys), 4.19 (1H, t $J=6.6 \mathrm{~Hz}, \mathrm{CH}-F m o c), 4.39$ $\left(2 \mathrm{H}, \mathrm{d} J=5.2 \mathrm{~Hz}, \mathrm{CH}_{2}\right.$-Fmoc), 4.58 (1H, br.t, $\left.\mathrm{NH}(\varepsilon)-\mathrm{Lys}\right), 5.47$ (1H, br.t, NH- hexadecyl), 6.09 (1H, br.d, NH( $\alpha)$-Lys), $7.29(3 \mathrm{H}$, t $J=7.4 \mathrm{~Hz}$, Ar-Fmoc), 7.38 (3H, t $J=7.3 \mathrm{~Hz}$, Ar-Fmoc), 7.57 (2H, d $J=7.1 \mathrm{~Hz}$, Ar-Fmoc), 7.75 (2H, d $J=7.4 \mathrm{~Hz}$, Ar-Fmoc). ${ }^{13} \mathrm{C}$ NMR $\delta_{\mathrm{C}}$ ppm: 14.09, 22.52, 22.68, 24.93, $26.88(\times 2), 28.43(\times 3), 29.26$, $29.35,29.50,29.55,29.65(\times 7), 31.92,32.16,33.96,39.64,47.20$, $54.93,67.03,78.89,119.98(\times 2), 125.04(\times 2), 127.08(\times 2), 127.73$ $(\times 2), 141.32(\times 2), 143.79(\times 2), 156.20,171.45$.

$N(\alpha)-17^{3}$ (Pyropheophorbide a) carboxamido-N(E)-Boc-Lyshexadecyl amide 8 . The mixture of amide $7(1.512 \mathrm{~g}, 2.19 \mathrm{mmol})$, piperidine $(220 \mu \mathrm{L}, 3 \mathrm{mmol})$ and dry DMF $(20 \mathrm{~mL})$ was stirred for $1 \mathrm{~h}$, then poured into ice water $(200 \mathrm{~mL})$, stirred for $20 \mathrm{~min}$, the resulted precipitate was filtered, washed with water and dried to obtain $N(\varepsilon)$-Boc-Lys-hexadecyl amide $(904 \mathrm{mg}, 1.92 \mathrm{mmol}$, $88 \%$ ) as white solid. HRMS, calculated for $\mathrm{C}_{27} \mathrm{H}_{56} \mathrm{~N}_{3} \mathrm{O}_{3}^{+}: 470.4316$, found: 470.4313. ${ }^{1} \mathrm{H}$ NMR $\delta_{\mathrm{H}} \mathrm{ppm}: 0.86\left(3 \mathrm{H}, \mathrm{t} J=6.7 \mathrm{~Hz}, \mathrm{CH}_{3}-\right.$ hexadecyl), $1.09\left(2 \mathrm{H}, \mathrm{m},\left(\mathrm{CH}_{2}\right)_{2} \mathrm{CH}_{2}\left(\mathrm{CH}_{2}\right)_{12} \mathrm{CH}_{3}\right), 1.24(26 \mathrm{H}, \mathrm{m}$, $\left.\mathrm{CH}_{2} \mathrm{CH}_{2} \mathrm{CH}_{2}\left(\mathrm{CH}_{2}\right)_{12} \mathrm{CH}_{3}\right), 1.42\left(9 \mathrm{H}, \mathrm{s}, \mathrm{CH}_{3}-\mathrm{Boc}\right), 3.10(2 \mathrm{H}, \mathrm{q}$

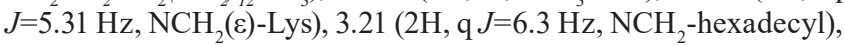
$3.32\left(1 \mathrm{H}\right.$, dd $J_{1}=4.3 \mathrm{~Hz}, J=7.7 \mathrm{~Hz}, \mathrm{CH}(\alpha)$-Lys), $4.17(1 \mathrm{H}$, br.t, NHhexadecyl), $4.56\left(1 \mathrm{H}\right.$, br.t, $\mathrm{NH}(\varepsilon)$-Lys). ${ }^{13} \mathrm{C}$ NMR $\delta_{\mathrm{C}}$ ppm: 14.08 , $22.66,22.87,24.94,25.64,26.97,28.42(\times 3), 29.30,29.67(\times 8)$, $29.92,31.91,34.62,39.08,40.18(\times 2), 49.08,55.06,79.09,156.08$, 174.65 .

The solution of pyropheophorbide $a(300 \mathrm{mg}, 0.56 \mathrm{mmol})$ and DCC $(120 \mathrm{mg}, 0.58 \mathrm{mmol})$ in dry dichloromethane $(25 \mathrm{~mL})$ was stirred for $30 \mathrm{~min}$, then $N(\varepsilon)$-Boc-Lys-hexadecyl amide (263 mg, 0,56 mmol) was added and the mixture was stirred for $40 \mathrm{~min}$ more, then evaporated to dryness, and the residue was separated by silica gel flash chromatography in dichloromethaneacetone (9:1) mixture to obtain compound 8 (329 $\mathrm{mg}, 0,33 \mathrm{mmol}$, $60 \%$ ) as black foam. HRMS, calculated for $\mathrm{C}_{60} \mathrm{H}_{88} \mathrm{~N}_{7} \mathrm{O}_{5}^{+}: 986.6841$; found: 986.6844. ${ }^{1} \mathrm{H}$ NMR $\delta_{\mathrm{H}}$ ppm: $-1.76(1 \mathrm{H}$, br.s, $\mathrm{NH}), 0.86(3 \mathrm{H}$, t $J=6.9 \mathrm{~Hz}, \mathrm{CH}_{3}$-hexadecyl), $1.18\left(28 \mathrm{H}, \mathrm{m}, \mathrm{CH}_{2}\left(\mathrm{CH}_{2}\right)_{14} \mathrm{CH}_{3}\right), 1.29$ $\left(9 \mathrm{H}, \mathrm{s}, \mathrm{CH}_{3}-\mathrm{Boc}\right), 1.66\left(3 \mathrm{H}, \mathrm{t} J=7.6 \mathrm{~Hz}, \mathrm{H}-8^{2}{ }^{2}\right), 1.78(3 \mathrm{H}, \mathrm{d} J=7.3 \mathrm{~Hz}$, $\mathrm{H}-18^{1}$ ), 2.89 (2H, m, $\mathrm{NCH}_{2}$-hexadecyl), $3.09(2 \mathrm{H}, \mathrm{q} J=4.7 \mathrm{~Hz}$, $\mathrm{NCH}_{2}(\varepsilon)$-Lys), 3.22, 3.38, 3.58 (each 3H, s, H-2 ${ }^{1}, \mathrm{H}^{-1}{ }^{1}, \mathrm{H}^{-12^{1}}$ '), 4.11 $\left(1 \mathrm{H}, \mathrm{m}, \mathrm{H}-17^{\prime}\right), 4.28\left(1 \mathrm{H}, \mathrm{m}, \mathrm{H}-17^{\prime}\right.$ '), 4.47 (1H, m, H- $8^{\prime}$ ), $4.54(1 \mathrm{H}$, br. t, $\mathrm{NH}(\varepsilon)$-Lys), 5.04, 5.25 (each $1 \mathrm{H}, \mathrm{d} J=20.0 \mathrm{~Hz}, \mathrm{H}-15^{\prime}$ ), 6.00 $\left(1 \mathrm{H}\right.$, br. d, $\mathrm{NH}(\alpha)$-Lys), $6.15\left(1 \mathrm{H}, \mathrm{dd} J=11.7 \mathrm{~Hz}, J=1.4 \mathrm{~Hz}, \mathrm{H}-3^{2}\right.$, trans), 6.15 (br.t, $1 \mathrm{H}, \mathrm{NH}-$ hexadecyl), $6.24(1 \mathrm{H}$, dd $J=17.9 \mathrm{~Hz}$, $\left.J_{2}=1.4 \mathrm{~Hz}, \mathrm{H}-3^{2}{ }^{2}, c i s\right), 7.96\left(1 \mathrm{H}, \mathrm{dd} J_{1}=11.6 \mathrm{~Hz}, J_{2}=17.8 \mathrm{~Hz}, \mathrm{H}^{2} 3^{1}{ }^{\prime}\right)$, 8.55, 9.36, 9.42 (each $1 \mathrm{H}, \mathrm{s}, \mathrm{H}-5$ ', H-10', H-20'). ${ }^{13} \mathrm{C}$ NMR $\delta_{\mathrm{C}} \mathrm{ppm}$ : $11.21,12.08,14.09,17.31,19.46,22.35,22.67,23.09,26.83,28.31$ $(\times 3), 29.63(\times 14), 29.98,31.58,31.90,32.40,39.53,39.79,48.06$, $49.98,51.68,52.89,78.98,93.31,97.11,103.91,106.33,122.62$, $128.59,129.12(\times 2), 130.55,131.74,135.96,136.28,137.85,141.64$, 144.81, 149.11, 156.08, $160.63(\times 2), 171.35,171.71,172.32,196.08$.

$N(\alpha)-17$ (Pyropheophorbide a) carboxamido-N(E)21 '"(17' $\beta$-hydroxy-3"'-oxopregn-4"'-ene-21"'-oyl) amido-Lyshexadecyl amide (conjugate 1). The mixture of compound $\mathbf{8}$ (329 $\mathrm{mg}, 0.33 \mathrm{mmol}$ ), dioxane $\left(10 \mathrm{~mL}\right.$ ) and $30 \%$ aqueous $\mathrm{H}_{2} \mathrm{SO}_{4}$ was stirred for $45 \mathrm{~min}$, the removal of Boc-group being controlled by TLC. Thereafter the mixture was poured into the mixture of water $(30 \mathrm{~mL})$ and chopped ice $(30 \mathrm{~g})$, neutralized with $\mathrm{NH}_{4} \mathrm{OH}$, and extracted with dichloromethane $(3 \times 25 \mathrm{~mL})$. The combined extract was washed with brine $(30 \mathrm{~mL})$, dried over $\mathrm{Na}_{2} \mathrm{SO}_{4}$ and evaporated to obtain $N(\alpha)-17^{\prime}$ (pyropheophorbide a) carboxamido-Lys-hexadecyl amide (284 mg, $0.32 \mathrm{mmol}, 97 \%$ ) as black solid. HRMS, calculated for $\mathrm{C}_{55} \mathrm{H}_{80} \mathrm{~N}_{7} \mathrm{O}_{3}^{+}$: 886.6317; found: $886.6318 .{ }^{1} \mathrm{H}$ NMR $\delta_{\mathrm{H}}$ ppm: $-1.72(1 \mathrm{H}$, br.s, $\mathrm{NH}), 0.86(3 \mathrm{H}$, t $J=6.9 \mathrm{~Hz}, \mathrm{CH}_{3}$-hexadecyl), $1.19\left(28 \mathrm{H}, \mathrm{m}, \mathrm{CH}_{2}\left(\mathrm{CH}_{2}\right)_{14} \mathrm{CH}_{3}\right), 1.67$ $\left(3 \mathrm{H}, \mathrm{t} J=7.6 \mathrm{~Hz}, \mathrm{H}-8^{2}\right), 1.77$ ( $\left.3 \mathrm{H}, \mathrm{d} J=7.3 \mathrm{~Hz}, \mathrm{H}-18^{1}{ }^{\prime}\right), 3.12(2 \mathrm{H}$, q $J=4.67 \mathrm{~Hz}, \mathrm{NCH}_{2}(\varepsilon)$-Lys), 3.21, 3.38, 3.59 (each $3 \mathrm{H}, \mathrm{s}, \mathrm{H}-2^{1}$, H-7 $\left.{ }^{1}, \mathrm{H}-12^{1}{ }^{\prime}\right), 4.20$ (1H, br.t, NH-hexadecyl), 4.28 (1H, m, H-17' $\left.{ }^{1}\right)$, $4.45\left(1 \mathrm{H}, \mathrm{m}, \mathrm{H}-8^{1}{ }^{\prime}\right), 5.04,5.23$ (each $1 \mathrm{H}, \mathrm{d} J=19.9 \mathrm{~Hz}, \mathrm{H}-15^{\prime}$ '), 5.92 (1H, br.d, $\mathrm{NH}(\alpha)$-Lys), $6.15\left(1 \mathrm{H}\right.$, dd $J_{1}=11.5 \mathrm{~Hz}, J_{2}=1.4 \mathrm{~Hz}, \mathrm{H}-3^{2}$, trans $), 6.26\left(1 \mathrm{H}, \mathrm{dd} J=18.0 \mathrm{~Hz}, J_{2}=1.4 \mathrm{~Hz}, \mathrm{H}-3^{2}\right.$, cis $), 7.97(1 \mathrm{H}, \mathrm{dd}$ $J=11.7 \mathrm{~Hz}, J=17.8 \mathrm{~Hz}, \mathrm{H}-3^{1}{ }^{\prime}$ ), 8.52, 9.34, 9.41 (each $1 \mathrm{H}, \mathrm{s}, \mathrm{H}-5^{\prime}$, H-10', H-20'). ${ }^{13} \mathrm{C}$ NMR $\delta_{\mathrm{C}}$ ppm: $11.31,12.05,12.15,14.18,17.49$, $19.53,22.58,22.77,23.17,23.82,26.95(\times 10), 32.01,32.56,32.80$, $39.48,39.61,41.48,48.13,50.08,50.92,51.73,53.19,93.03,97.24$ 104.07, 106.15, 122.58, 128.24, $129.31(\times 2), 131.62,135.90,136.14$, $137.71,137.92,141.45,141.63,145.08,148.87,150.86,155.35$, $160.40,171.62,172.14,196.19$

DCC $(100 \mathrm{mg}, 0.49 \mathrm{mmol})$ was added to the stirred solution of 17ß-hydroxy-3-oxopregn-4-en-21-oic acid 4 in dry dichloromethane $(15 \mathrm{~mL})$ and the mixture was stirred for $10 \mathrm{~min}$; then $N(\alpha)-17^{\prime}$ (pyropheophorbide a) carboxamido-Lys-hexadecyl amide (217 $\mathrm{mg}, 0.25 \mathrm{mmol}$ ) was added, and the mixture was stirred for $12 \mathrm{~h}$ more. Thereafter the mixture was evaporated, the residue was separated by silica gel flash chromatography in dichloromethane - acetone - AcOH (84:15:1) mixture to obtain compound 1 (141 mg, $0.12 \mathrm{mmol}, 47 \%$ ). HRMS, calculated for $\mathrm{C}_{76} \mathrm{H}_{108} \mathrm{~N}_{7} \mathrm{O}_{6}^{+}$: 1214.8356; found: $1214.8363 .{ }^{1} \mathrm{H}$ NMR $\delta_{\mathrm{H}}$ ppm: $-1.67(1 \mathrm{H}$, br.s, $\mathrm{NH}), 0.71$ (3H, s, H-18'), 0.86 (3H, t $J=7.0 \mathrm{~Hz}, \mathrm{CH}_{3}$-hexadecyl), 0.95 (3H, s, H-19') 1.17 (28H, m, $\left.\mathrm{CH}_{2}\left(\mathrm{CH}_{2}\right)_{14} \mathrm{CH}_{3}\right), 1.60(3 \mathrm{H}, \mathrm{t}$ $\left.J=7.6 \mathrm{~Hz}, \mathrm{H}-8^{2}{ }^{\prime}\right), 1.74\left(3 \mathrm{H}, \mathrm{d} J=7.2 \mathrm{~Hz}, \mathrm{H}-18^{1}{ }^{\prime}\right), 2.34$ (2H, AB system, $\mathrm{H}-20$ '), 3.11 (2H, q $J=6.5 \mathrm{~Hz}, \mathrm{NCH}_{2}(\varepsilon)$-Lys), 3.14, 3.33, 3.40 (each 3H, s, H-2 ${ }^{1}, \mathrm{H}_{-1}{ }^{1}, \mathrm{H}-12^{1}$ ') $4.24\left(1 \mathrm{H}, \mathrm{m}, \mathrm{H}-17^{1}\right.$ ) $), 4.39(1 \mathrm{H}$, m, H- ${ }^{1}$ ') $, 4.88,5.13$ (each $\left.1 \mathrm{H}, \mathrm{d} J=20.0 \mathrm{~Hz}, \mathrm{H}-15^{1}{ }^{\prime}\right), 5.28(1 \mathrm{H}, \mathrm{s}$, 17 '-OH), $5.48\left(1 \mathrm{H}, \mathrm{s}, \mathrm{H}-4\right.$ '”), $6.12\left(1 \mathrm{H}, \mathrm{dd} J_{1}=11.6 \mathrm{~Hz}, J_{2}=1.4 \mathrm{~Hz}\right.$, H-3 ${ }^{2}$, trans $), 6.22\left(1 \mathrm{H}, \mathrm{dd} J=17.9 \mathrm{~Hz}, J=1.4 \mathrm{~Hz}, \mathrm{H}-3^{2}\right.$, cis $), 6.40$ $(1 \mathrm{H}$, br.d, $\mathrm{NH}(\alpha)$-Lys), $6.46(1 \mathrm{H}$, br. t, NH-hexadecyl), $6.72(1 \mathrm{H}$, br.t, $\mathrm{NH}(\varepsilon)$-Lys), $7.88\left(1 \mathrm{H}\right.$, dd $\left.J=14.7 \mathrm{~Hz}, J=17.8 \mathrm{~Hz}, \mathrm{H}-3^{1}{ }^{\prime}\right), 8.46$, 9.19, 9.23 (each $1 \mathrm{H}, \mathrm{s}, \mathrm{H}-5, \mathrm{H}-10{ }^{\prime}, \mathrm{H}-20{ }^{\prime}$ ). ${ }^{13} \mathrm{C}$ NMR $\delta_{\mathrm{C}}$ ppm: $11.14,11.83,12.03,13.73,14.10,17.12,17.35,19.30,20.42,22.61$, $22.67,22.85,23.44,26.86,28.62,29.21,29.63(\times 10), 30.36,31.44$, $31.49,31.76,31.91,32.52,32.78,33.78,35.48,36.05,36.10,38.40$, $38.61,39.62,42.51,46.04,48.02,49.80,50.01,51.45,52.85,53.51$, $81.90,92.93,97.12,103.93,105.71,122.56,123.66,128.22,129.05$, $129.98,131.64,135.88,136.04,136.33,137.63,141.67,145.01$, $148.89,150.76,155.38,160.19,170.93,171.45,171.66,172.66$, 173.41, 196.33, 199.24.

$N(\varepsilon)-17^{3}$ (Pyropheophorbide a)carboxamido-Lys-hexadecyl amide 9. The mixture of amide 7 (911 $\mathrm{mg}, 1.32 \mathrm{mmol})$, dichloromethane $(30 \mathrm{~mL})$, and TFA $(10 \mathrm{~mL})$ was stirred for $30 \mathrm{~min}$, evapotated to dryness, residue was dissolved in dichloromethane $(30 \mathrm{~mL})$, the solution was washed with saturated $\mathrm{NaHCO}_{3}$ solution $(20 \mathrm{~mL})$, brine $(20 \mathrm{~mL})$, dried over $\mathrm{Na}_{2} \mathrm{SO}_{4}$, and evaporated to obtain $N(\alpha)$-Fmoc-Lys-hexadecyl amide $(766 \mathrm{mg}, 1.29 \mathrm{mmol}$, $98 \%$ ) as black film. HRMS, calculated for $\mathrm{C}_{37} \mathrm{H}_{58} \mathrm{~N}_{3} \mathrm{O}_{3}^{+}: 592.4473$; found: 592.4477. ${ }^{1} \mathrm{H}$ NMR $\delta_{\mathrm{H}}$ ppm: $0.87\left(3 \mathrm{H}, \mathrm{t} J=6.3 \mathrm{~Hz}, \mathrm{CH}_{3}\right.$ hexadecyl), $1.36\left(28 \mathrm{H}, \mathrm{m}, \mathrm{CH}_{2}\left(\mathrm{CH}_{2}\right)_{14} \mathrm{CH}_{3}\right), 2.69\left(2 \mathrm{H}, \mathrm{m}, \mathrm{CH}_{2}(\varepsilon)-\right.$ Lys), 3.22 (2H, m, NCH -hexadecyl), $4.07(1 \mathrm{H}, \mathrm{m}, \mathrm{CH}(\alpha)$-Lys), $4.20(1 \mathrm{H}, \mathrm{t} J=6.6 \mathrm{~Hz}, \mathrm{CH}-\mathrm{Fmoc}), 4.40\left(2 \mathrm{H}, \mathrm{d} J=5.9 \mathrm{~Hz}, \mathrm{CH}_{2}-\mathrm{Fmoc}\right)$, $5.50(1 \mathrm{H}$, br.t, NH-hexadecyl), $6.16(1 \mathrm{H}$, br. d, NH( $\alpha)$-Lys), 7.30 (3H, t $J=7.4 \mathrm{~Hz}, \mathrm{Ar}-\mathrm{Fmoc}$ ), 7.39 (3H, t $J=7.4 \mathrm{~Hz}, \mathrm{Ar}-\mathrm{Fmoc}$ ), 7.57 (2H, d $J=7.4 \mathrm{~Hz}, \mathrm{Ar}-\mathrm{Fmoc}), 7.75(2 \mathrm{H}, \mathrm{d} J=7.6 \mathrm{~Hz}, \mathrm{Ar}-\mathrm{Fmoc}) .{ }^{13} \mathrm{C}$ NMR $\delta_{\mathrm{C}}$ ppm: 14.18, 22.72, 22.77, 26.99, 29.35, 29.44, $29.78(\times 11)$, 
$32.01,32.56,39.70,41.66,47.32,55.06,67.05,120.08(\times 2), 125.10$ $(\times 2), 127.17(\times 2), 127.83(\times 2), 141.43(\times 2), 143.90(\times 2), 171.50$.

The solution of pyropheophorbide a $\mathbf{3}(250 \mathrm{mg}, 0,47 \mathrm{mmol})$ and DCC $(97 \mathrm{mg}, 0.47 \mathrm{mmol})$ in dry dichloromethane $(25 \mathrm{~mL})$ was stirred for $30 \mathrm{~min}$, then $N(\alpha)$-Fmoc-Lys-hexadecyl amide ( $227 \mathrm{mg}, 470 \mu \mathrm{mol}$ ) was added, the mixture was stirred for $45 \mathrm{~min}$ more, and evaporated. TLC analysis revealed partial deletion of Fmoc-group in resulted product. The residue was dissolved in DMF $(5 \mathrm{~mL})$, then piperidine $(37 \mu \mathrm{L}, 0.5 \mathrm{mmol})$ was added, the mixture was stirred for $1 \mathrm{~h}$, diluted with dichloromethane $(30 \mathrm{~mL})$, washed with water $(2 \times 10 \mathrm{~mL})$, dried over $\mathrm{Na}_{2} \mathrm{SO}_{4}$, and evaporated. The residue was separated by silica gel flash chromatography in dichloromethane-acetone (93:7) mixture to obtain compound 9 (146 mg, $170 \mu \mathrm{mol}, 35 \%)$. HRMS, calculated for $\mathrm{C}_{55} \mathrm{H}_{80} \mathrm{~N}_{7} \mathrm{O}_{3}^{+}:$: 886.6317; found: 886.6307. ${ }^{1} \mathrm{H}$ NMR $\delta_{\mathrm{H}}$ ppm: -1.69 (1H, br.s, $\mathrm{NH}), 0.86\left(3 \mathrm{H}, \mathrm{t} J=7.5 \mathrm{~Hz}, \mathrm{CH}_{3}\right.$-hexadecyl), 1.23 $\left(28 \mathrm{H}, \mathrm{m}, \mathrm{CH}_{2}\left(\mathrm{CH}_{2}\right)_{14} \mathrm{CH}_{3}\right), 1.65\left(3 \mathrm{H}, \mathrm{t} J=7.6 \mathrm{~Hz}, \mathrm{H}-8^{2}\right), 1.78(3 \mathrm{H}$, d $\left.J=7.3 \mathrm{~Hz}, \mathrm{H}-18^{1}{ }^{1}\right), 2.98$ ( $2 \mathrm{H}, \mathrm{q} J=6.2 \mathrm{~Hz}, \mathrm{NCH}_{2}(\varepsilon)$-Lys), 3.20, $3.38,3.51$ (each $3 \mathrm{H}, \mathrm{s}, \mathrm{H}-2^{1}, \mathrm{H}-7^{1}, \mathrm{H}-12^{1}$ ') 4.21 (1H, m, H-17' '), $4.50\left(1 \mathrm{H}, \mathrm{m}, \mathrm{H}-8^{1}\right.$ ) $, 5.05,5.23$ (each, $1 \mathrm{H}, \mathrm{d} J=19.9 \mathrm{~Hz}, \mathrm{H}-15^{1}$ ), $5.42\left(1 \mathrm{H}\right.$, br.t, NH-hexadecyl), $6.15\left(1 \mathrm{H}\right.$, dd $J_{1}=11.6 \mathrm{~Hz}, J_{2}=1.4 \mathrm{~Hz}$, $\mathrm{H}-3^{2}$, , trans $), 6.27\left(1 \mathrm{H}, \mathrm{dd} J=17.8 \mathrm{~Hz}, J_{2}=1.4 \mathrm{~Hz}, \mathrm{H}-3^{2}{ }^{2}\right.$, cis $), 7.14$ (1H, br.t, NH(ع)-Lys), $7.97\left(1 \mathrm{H}\right.$, dd $\left.J=11.5 \mathrm{~Hz}, J=17.8 \mathrm{~Hz}, \mathrm{H}-3^{1}{ }^{\prime}\right)$, 8.52, 9.34, 9.35 (each 1H, s, H-5', H-10', H-20'). ${ }^{13} \mathrm{C}$ NMR $\delta_{\mathrm{C}} \mathrm{ppm}$ : $11.30,12.00,12.16,14.18,17.47,19.51,22.76,23.07,23.17,23.88$, $26.96,28.85,29.03,29.75(\times 8), 30.44,30.49,32.00,33.04,34.30$, $38.93,39.07,48.19,50.10,51.87,54.81,93.11,97.20,104.06,106.17$, $122.62,128.28,128.90,129.29,130.94,131.67,135.95,136.12$, $136.30,141.64,145.08,149.06,150.82,155.29,160.60,171.95$, $172.39,174.54,196.36$.

$N(\alpha)$-21'"(17'" $\beta$-Hydroxy-3'"-oxopregn-4',-ene-21''-oyl) amido-N $(\varepsilon)-\left(17^{3}\right.$ (pyropheophorbide a)-carboxamido-Lyshexadecyl amide (conjugate 2). The mixture of compounds 9 (65 mg, $73 \mu \mathrm{mol}), 4$ (26 mg, $73 \mu \mathrm{mol})$, and DCC (17 mg, $80 \mu \mathrm{mol})$ was stirred for $25 \mathrm{~min}$, the reaction being controlled by TLC. Thereafter the mixture was evaporated, the residue was applied on the top of silica gel column, the column was washed with $\mathrm{CHCl}_{3}-$ acetone $-\mathrm{AcOH}$ (85:14:1) mixture, then target product was eluted with $\mathrm{CHCl}_{3}$ - acetone - AcOH (79:20:1). The isolated crude conjugate was additionally purified by silica gel flash chromatography in $\mathrm{CHCl}_{3}-\mathrm{MeOH}-\mathrm{AcOH}$ (93:6:1) mixture to obtain conjugate 2 (47 mg, $39 \mu \mathrm{mol}, 53 \%$ ) as black powder. HRMS, calculated for $\mathrm{C}_{76} \mathrm{H}_{108} \mathrm{~N}_{7} \mathrm{O}_{6}^{+}: 1214.8356$; found: $1214.8362 .{ }^{1} \mathrm{H}$ NMR $\delta_{\mathrm{H}} \mathrm{ppm}:-1.66$ (1H, br.s, NH), 0.70 (3H, s, H-18"), $0.86\left(3 \mathrm{H}, \mathrm{t} J=7.0 \mathrm{~Hz}, \mathrm{CH}_{3}-\right.$ hexadecyl), $0.91(3 \mathrm{H}, \mathrm{s}, \mathrm{H}-19$ ') $), 1.21\left(28 \mathrm{H}, \mathrm{m}, \mathrm{CH}_{2}\left(\mathrm{CH}_{2}\right)_{14} \mathrm{CH}_{3}\right)$, 1.61 ( $3 \mathrm{H}, \mathrm{t} J=7.6 \mathrm{~Hz}, \mathrm{H}-8^{2}$ '), 1.76 ( $3 \mathrm{H}, \mathrm{d} J=7.1 \mathrm{~Hz}, \mathrm{H}-18^{1}$ ) $), 2.29$ ( $2 \mathrm{H}$, AB system, $\mathrm{H}-20$ "'), 3.11 ( $2 \mathrm{H}, \mathrm{q} J=6.5 \mathrm{~Hz}, \mathrm{NCH}_{2}(\varepsilon)$-Lys), 3.16, 3.34, 3.38 (each $3 \mathrm{H}, \mathrm{s}, \mathrm{H}-2^{1}, \mathrm{H}-7^{1}, \mathrm{H}-12^{1}$ ), 4.30 (1H, m, H-17' $\left.{ }^{\prime}\right), 4.44$ $\left(1 \mathrm{H}, \mathrm{m}, \mathrm{H}-8^{1}\right.$ ) $), 4.97,5.14$ (each $1 \mathrm{H}, \mathrm{d} J=19.9 \mathrm{~Hz}, \mathrm{H}-15^{1}$ '), 5.49 (1H, s, H-4"), 5.80 (1H, br.t, NH-hexadecyl), $6.12(1 \mathrm{H}$, dd $J=11,5 \mathrm{~Hz}$, $J_{2}=1.4 \mathrm{~Hz}, \mathrm{H}-3^{2}$, trans $), 6.22\left(1 \mathrm{H}, \mathrm{dd} J_{1}=18.0 \mathrm{~Hz}, J_{2}=1.4 \mathrm{~Hz}, \mathrm{H}-3^{2}\right.$, cis), 6.65 (1H, br. t, NH(E)-Lys), 7.15 (1H, br.d, NH( $\alpha$ )-Lys), 7.89 $\left(1 \mathrm{H}\right.$, dd $J_{1}=14.7 \mathrm{~Hz}, J_{2}=17.9 \mathrm{~Hz}, \mathrm{H}^{-1}{ }^{\prime}{ }^{\prime}$ ), 8.47, 9.22, 9.25 (each $1 \mathrm{H}$, s, H-5', H-10', H-20'). ${ }^{13} \mathrm{C}$ NMR $\delta_{\mathrm{C}}$ ppm: $11.25,11.89,12.12,13.88$, $14.17,17.13,17.43,19.43,20.43,22.75,23.08,23.52,26.97,28.97$, 29.36, 29.41, 29.51, 29.63, $29.75(\times 10), 30.80,31.33,31.47,31.58$, $31.99,32.58,33.40,33.84,35.45,35.71,36.15,38.41,38.79,39.72$, $42.92,46.28,48.14,49.93,50.12,51.82,53.13,53.40,81.14,93.80$, $97.20,104.06,105.74,122.67,123.80,127.97,129.12,130.04$, $131.73,135.99,136.17,136.44,137.74,141.78,145.12,149.06$, $150.87,155.50,160.50,170.77,171.55,171.96,172.80,173.41$, 196.40, 199.21.

\section{Molecular Modeling}

Conformation searches have been performed using molecular mechanics MMFF94 force field parameters in vacuo. OpenBabel package ${ }^{[18]}$ was employed for initial structure preparation and energy minimization. Simulated annealing molecular dynam- ics (MD) has been performed to sample low-energy conformation space of compounds $\mathbf{1 - 4}$, using NAMD ${ }^{[19]}$ software. Parameters and topology files were generated with the aid of SwissParam server ${ }^{[20]}$ on the basis of Merck force field. The annealing protocol consisted of $4 \mathrm{ps}$ high temperature runs at $500 \mathrm{~K}$ followed by 4 ps cooling down to $50 \mathrm{~K}$, with total of 200 annealing cycles scheduled in 32 processes. This procedure yielded 6400 local energy minima for each compound. Resulting structures were then optimized by energy minimization with MMFF94 potential. The VMD package ${ }^{[21]}$ was used for MD trajectory post-processing, analysis, and visualization.

\section{Solubilization of Conjugates 1 and 2}

Soya bean PC "Lipoid S-100" was purchased from "Lipoids", pluronic F68 - from "BASF".

Solubilization with Phosphatidyl Choline (PC). Calculated volumes of $10^{-2} \mathrm{M}$ solutions of $\mathrm{PC}$ and conjugate (either 1, or 2) in chloroform were mixed together to obtain solution conjugate /PC with ratio $1: 10$ (mg/mg, 6.7 molar $\%$ of conjugate). Mixed solutions were evaporated to dryness, and dissolved in $i \mathrm{PrOH}$ at $40{ }^{\circ} \mathrm{C}$ to obtain solutions with concentrations of conjugates equal to $10^{-3} \mathrm{M}$. Aliquots of heated isopropanolic solutions were injected during vortexing into 100-fold volume of PBS (for measuring of absorption spectra and particle size distributions) or in culture medium (for measuring of uptake and internalization of conjugates by cells).

Solubilization with Pluronic F68. Calculated volumes of $10^{-2} \mathrm{M}$ solutions of pluronic F68 and conjugates (either $\mathbf{1}$, or 2) in chloroform were mixed together to obtain solutions conjugate / pluronic with ratios 1:10 and 1:50 (mg/mg). Mixed solutions were evaporated to dryness, then calculated volumes of PBS, or culture medium were added to films, and the mixtures obtained were vortexed at $40{ }^{\circ} \mathrm{C}$ for $1 \mathrm{~min}$.

\section{Uptake and Internalization of Conjugates $\mathbf{1}$ and $\mathbf{2}$ in Prostate Carcinoma Cells}

The human prostate carcinoma LNCaP cells and human liver carcinoma Hep G2 cells were obtained from the American Type Culture Collection (Rockville, MD). Cells were propagated in culture dishes at the desired densities in RPMI 1640 medium supplemented with $10 \%$ fetal calf serum (FCS; Gibco, Grand Island, NY) and $1 \%$ penicillin/streptomycin (Gibco) in a $5 \% \mathrm{CO}_{2}$ atmosphere at $37{ }^{\circ} \mathrm{C}$ for $24 \mathrm{~h}$. Before experiments the cells were seeded in 6-well plates at a density of $10^{6}$ cells/well and incubated for $48 \mathrm{~h}$. The cells were incubated for $6 \mathrm{~h}$ with mixed micelles ( $25 \mu \mathrm{M}$ of conjugate), then medium was aspirated, cells were washed with cold PBS at $4{ }^{\circ} \mathrm{C}$, and lipids from each well were extracted with mixture hexane $i$ PrOH $(3: 2,3 \times 0.5 \mathrm{~mL})$, the cell pellets were used for measuring of cell protein concentrations. ${ }^{[23]}$ Lipid extracts were dried under nitrogen flow, residues were dissolved in $\mathrm{CH}_{2} \mathrm{Cl}_{2}(2 \mathrm{~mL})$ and the concentration of conjugates were determined from absorption spectra. All measurements were carried out in triplicates. The efficiency of cell labeling was expressed in terms of ratios of internalized conjugates (n mol/1 $\mathrm{mg}$ of cell protein).

\section{Results and Discussion}

\section{Chemical synthesis}

Conjugates $\mathbf{1}$ and $\mathbf{2}$ were synthesized according to Scheme 1; all condensation reactions were performed in the presence of DCC.

Commercially available $N(\alpha)$-Fmoc-N(E)-Boc-Lys 5 and hexadecyl amine $\mathbf{6}$ were condensed to obtain 


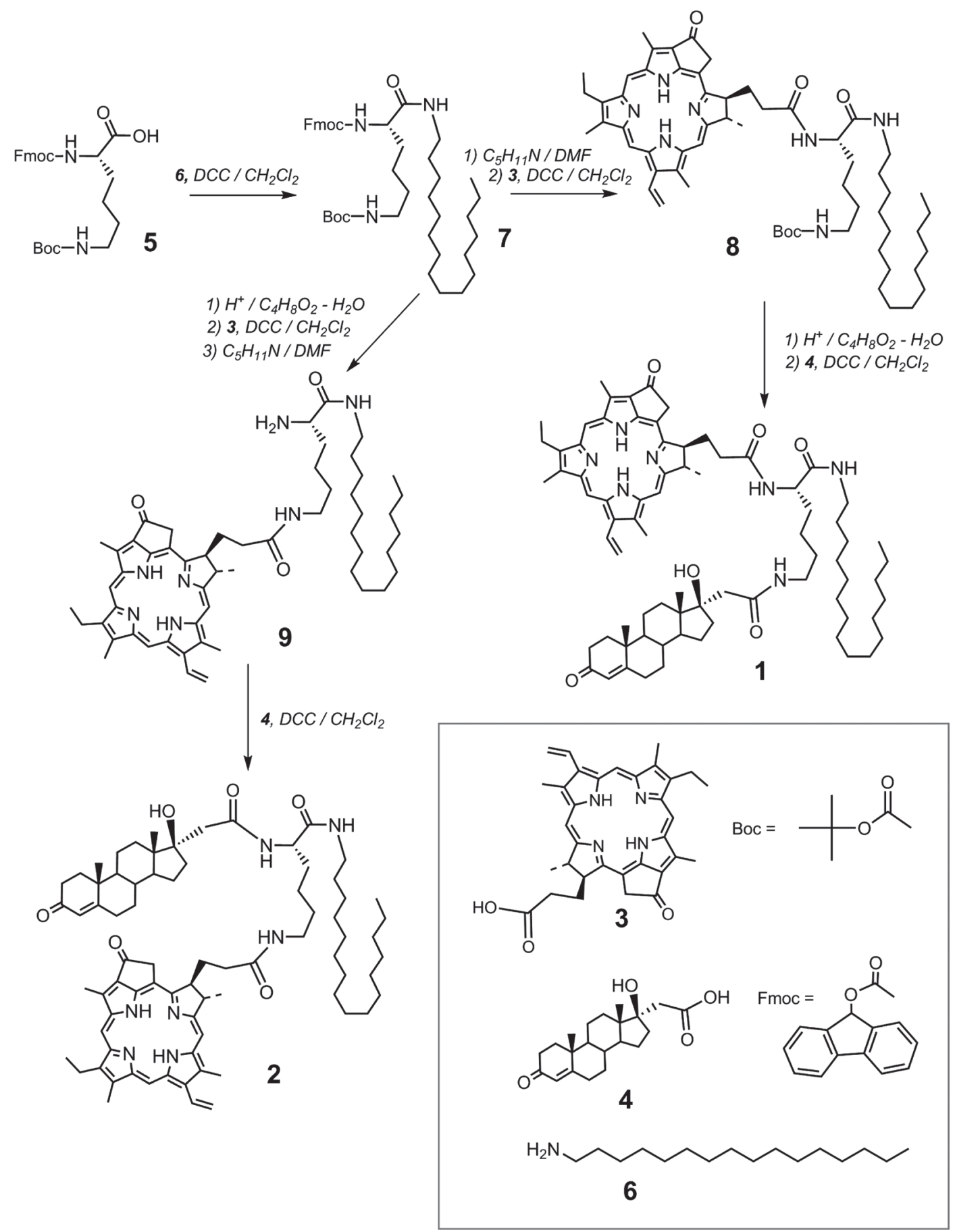

Scheme 1.

protected lysyl amide 7 in $87 \%$ yield. To prepare conjugate 1 amide 7 was consequently treated with piperidine to remove Fmoc-protecting group; the product was coupled with pyropheophorbide a $\mathbf{3}$; the obtained intermediate $\mathbf{8}$ was treated with acid to remove Boc-protecting group; and resulting amine was acylated with 17ß-hydroxy-3oxopregn-4-en-21-oic acid 4.

Our attempt to prepare conjugate $\mathbf{2}$ according to the same scheme was slightly successful because of racemization of $\mathrm{C} 17$ in 17-hydroxy-3-oxopregn-4-en21-oyl amides, which occurs in the presence of acid (under the conditions of removal of Boc-group). For this reason we changed the consequence of reactions as follows: initially we removed Boc-protective group in amide 7 and coupled obtained amine with pyropheophorbide $a \mathbf{3}$ (wherein the partial removal of Fmoc-protecting group was observed); then, after complete Fmoc-group deletion, the amine 9 was condensed with 17 $\beta$-hydroxy-3-oxopregn-4-en-21-oic acid 4 to get target conjugate 2 .

Both conjugates $\mathbf{1}$ and $\mathbf{2}$ were prepared as pure compounds, their structures were completely characterized by HRMS, ${ }^{1} \mathrm{H}$ NMR, ${ }^{13} \mathrm{C}$ NMR and absorption spectra. 
Table 1. Chemical shifts ( $\delta$, ppm).

\begin{tabular}{|c|c|c|c|c|c|c|c|c|c|}
\hline Conjugate & $\mathrm{H}-4 "$ & H-18” & H-19” & H-5, & $\mathrm{H}-10^{\prime}$ & H-20' & $\alpha-\mathrm{NH}$ & $\varepsilon-\mathrm{NH}$ & $\mathrm{NH}-\left(\mathrm{CH}_{2}\right)_{15} \mathrm{CH}_{3}$ \\
\hline 1 & $5.48, \mathrm{~s}$ & $0.71, \mathrm{~s}$ & $0.95, \mathrm{~s}$ & $9.23, \mathrm{~s}$ & $9.19, \mathrm{~s}$ & $8.46, \mathrm{~s}$ & 6.40 , br.d & 6.75 , br.t & 6.46 , br.t \\
\hline 2 & $5.49, \mathrm{~s}$ & $0.70, \mathrm{~s}$ & $0.91, \mathrm{~s}$ & $9.25, \mathrm{~s}$ & $9.22, \mathrm{~s}$ & $8.47, \mathrm{~s}$ & 7.15 , br.d & 6.56 , br.t & 5.80, br.t \\
\hline
\end{tabular}

\section{Spectral properties and molecular models of conjugates}

Chemical shifts values for some characteristic resonances in ${ }^{1} \mathrm{H}$ NMR spectra of conjugates $\mathbf{1}$ and $\mathbf{2}$ are presented in Table 1.

${ }^{1} \mathrm{H}$ NMR spectra of conjugates $\mathbf{1}$ and $\mathbf{2}$ demonstrated high field shifts for H-4" resonances in comparison with that of 17 $\beta$-hydroxy-3-oxopregn-4-en-21-oic acid 4. This effect was reported previously ${ }^{[17]}$ to be caused by influence of macrocycle on steroid moiety. Modest high field shifts for H-18" and H-19" resonances were observed in spectra of conjugates $\mathbf{1}$ and $\mathbf{2}$, however these shifts were weaker than those in spectra of bifunctional testosterone conjugate, reported earlier ${ }^{[17]}$ Chemical shifts for amide $\mathrm{N}-\mathrm{H}$ resonances strongly depended on the conjugate structure, while those for $\mathrm{H}-5$, H-10' and H-20' resonances in pyropheophorbide $a$ moieties differed insignificantly. The data presented in the Table 1 are thought to be in agreement with results of molecular modeling indicated differences in positional relationships of steroid and macrocycle moieties in conjugates $\mathbf{1}$ and $\mathbf{2}$.

Molecular modeling of conjugates $\mathbf{1}$ and $\mathbf{2}$ was performed by simulated annealing. Calculated ensembles of conformers, truncated at $10 \mathrm{kcal} / \mathrm{mol}$ above the lowest-energy conformer, are shown in the Figure 2; the lowest energy conformers are presented in Figure 3. The Fig- ure $2 \mathrm{~A}$ demonstrates that structures with steroid moiety hoisted over the surface of macrocycle, and hexadecyl chain located in its opposite side, are energetically favorable for conjugate 1. On the contrary, Figure $2 \mathrm{~B}$ reveals that three ensembles of low energy conformers differing in positions of steroid relatively to macrocycle, and random distribution of hexadecyl chain, are favored for conjugate 2 (Figure 2B). In both conjugates 18- and 19-methyl groups were mainly turned away from macrocycle.

Conformers presented in Figure 3 are stabilized by possibility of intramolecular hydrogen bonds formation. In the lowest energy conformers of both conjugates $\mathbf{1}$ and $\mathbf{2}$ hydrogen atom of steroid 17-hydroxyl group participates in hydrogen bond formation with oxygen of related 21-carboxamido group. Additionally, in the lowest energy conformer of conjugate 1 the oxygen atom of 17-hydroxyl group is located near nitrogen atom of hexadecyl amide, and thus may serve as proton acceptor to form the corresponding hydrogen bond (Figure 3A). In the lowest energy conformer of conjugate $\mathbf{2}$ nitrogen atom of hexadecyl amide is located near carbonyl group of pyropheophorbide $a$, and may be involved in formation of corresponding hydrogen bond. Generally, modeling results suggest a disposition of conjugates $\mathbf{1}$ and $\mathbf{2}$ to support intramolecular hydrogen bond network, which contributes to the stability of 'folded' conformers.
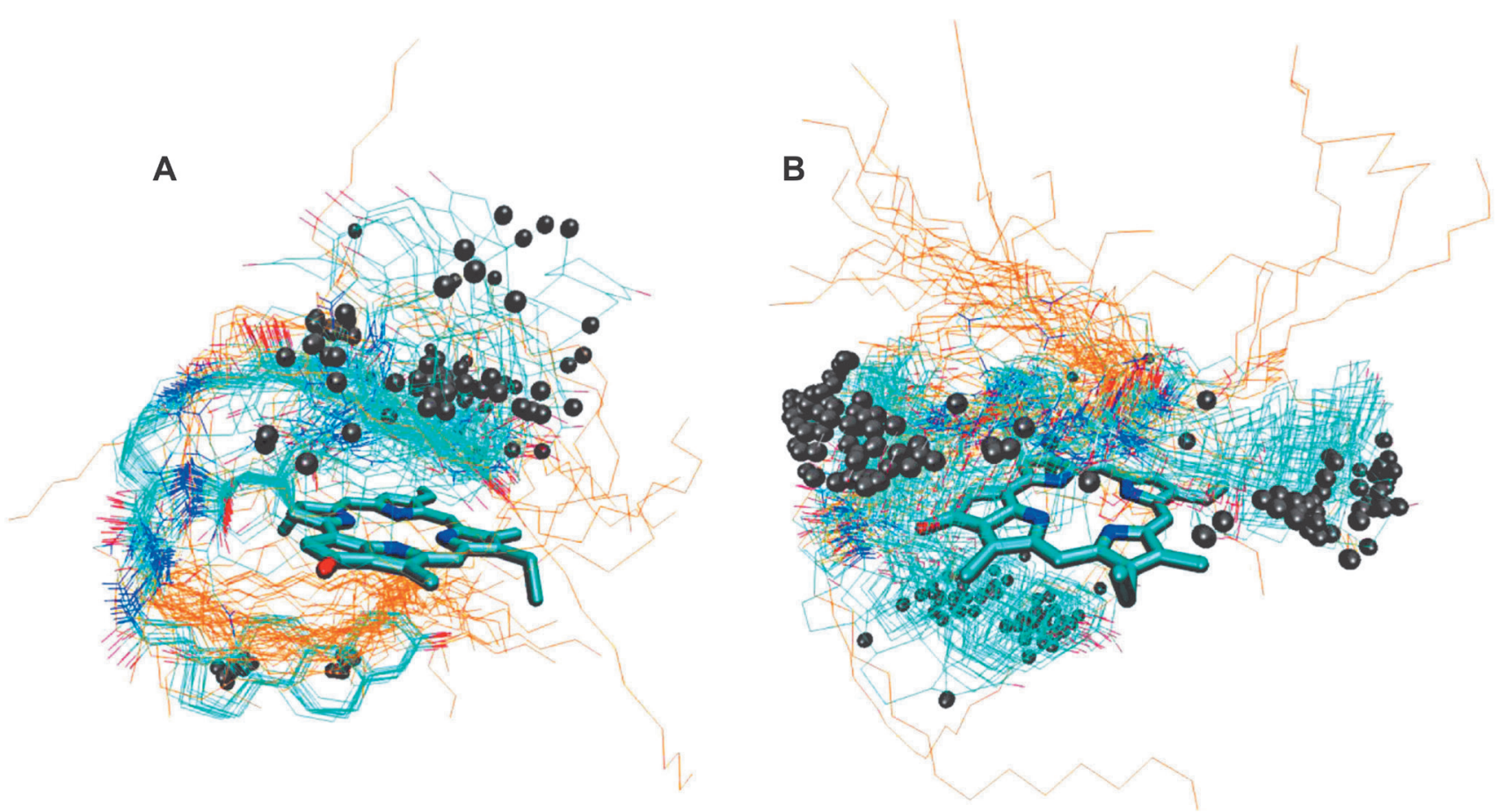

Figure 2. Ensembles of low energy conformers of conjugates 1 (A) and 2 (B); 18- and 19-methyl groups of steroid core are depicted as gray balls. 

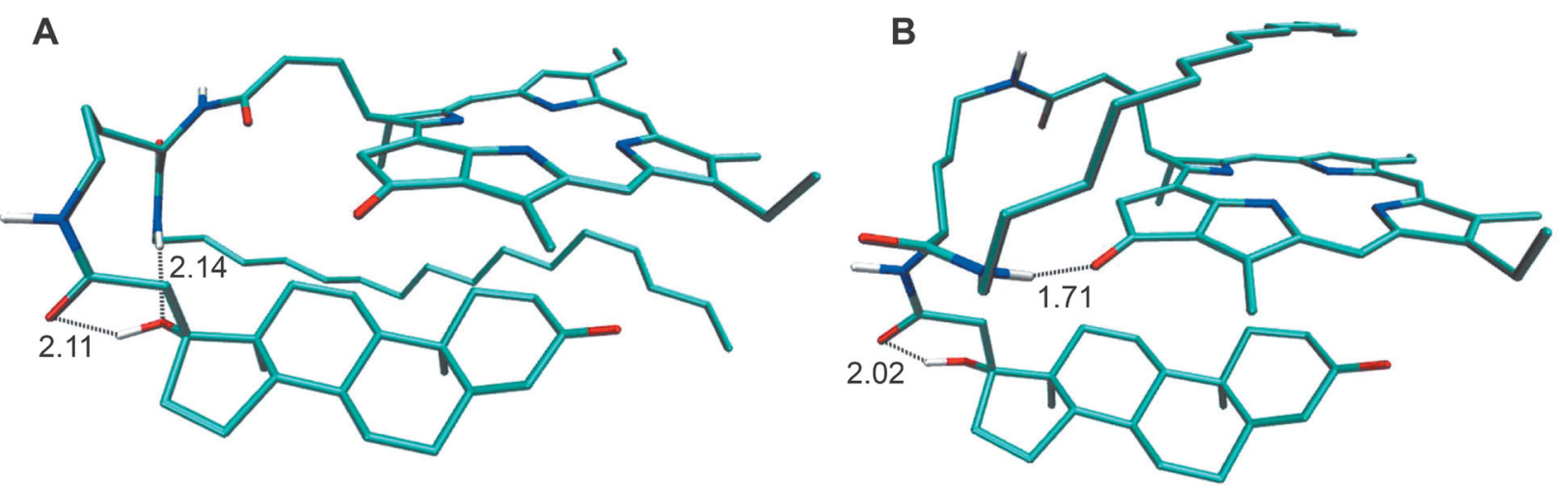

Figure 3. The lowest calculated energy conformers for conjugates 1 (A) and 2 (B). Short interatomic distances favorable for hydrogen bond formation are marked by hash lines; numbers indicate distance in Angstroms.

\section{Solubilization of conjugates in aqueous media and interaction with cultured cells}

The next task was investigation of solubilization of conjugates 1 and 2 in aqueous media. We checked two methods of solubilization: (i) injection of mixed solution conjugate and $\mathrm{PC}$ in $i \mathrm{PrOH}$ into aqueous buffer, which led to stable conjugate $-\mathrm{PC}$ micelles; ${ }^{[15]}$ (ii) hydration of mixed films conjugate - pluronic. ${ }^{[22]}$ Absorption spectra and particle size distribution (measured by laser scattering) were used to characterize obtained micelles.

We have prepared mixed micelles $\mathbf{1}-\mathbf{P C}$ and $\mathbf{2}-\mathbf{P C}$ with mass ratio conjugate/PC equal to $1: 10$ (which corresponded to concentration of 6.7 molar \% of conjugates); and micelles $\mathbf{1}$ - pl and $\mathbf{2}$ - pl with mass ratio conjugate/ pluronic equal to 1:10 and 1:50. Absorption spectra and particle size distribution for these preparations are presented in Figures 4 and 5, respectively.
The spectra of $\mathbf{1}$ - PC and $\mathbf{2}$ - PC micelles were nearly identical and highly resolved; the Soret bands had two maxima at $402 \mathrm{~nm}$ and $417 \mathrm{~nm}$ (the last one is known to be characteristic for aggregated form of conjugates); the long wave maxima had red shifts about $6 \mathrm{~nm}$ (compared to those for spectra of conjugates $\mathbf{1}$ and $\mathbf{2}$ in dichloromethane) and were observed at $674 \mathrm{~nm}$; the maxima at $516 \mathrm{~nm}$, $544 \mathrm{~nm}, 618 \mathrm{~nm}$ were clearly visible (Figure 4). The mean sizes were measured to be $123.3 \mathrm{~nm}$ and $108.0 \mathrm{~nm}$ for $\mathbf{1}-$ PC and 2- PC micelles, respectively. These mixed micelles possessed high stability - their absorption spectra and particle size distribution did not show any visible changes during the storage for 1 week.

On the contrary, spectra $\mathbf{1} \mathbf{- p l}$ and $\mathbf{2}-\mathbf{p l}$ even at a ratio conjugate/pluronic 1:50 were insufficiently resolved (Figure 4); the Soret bands were broad; the long wave maxima had additional shoulder near $710 \mathrm{mn}$, that indicated association of macrocycle chromophores with formation of stacked

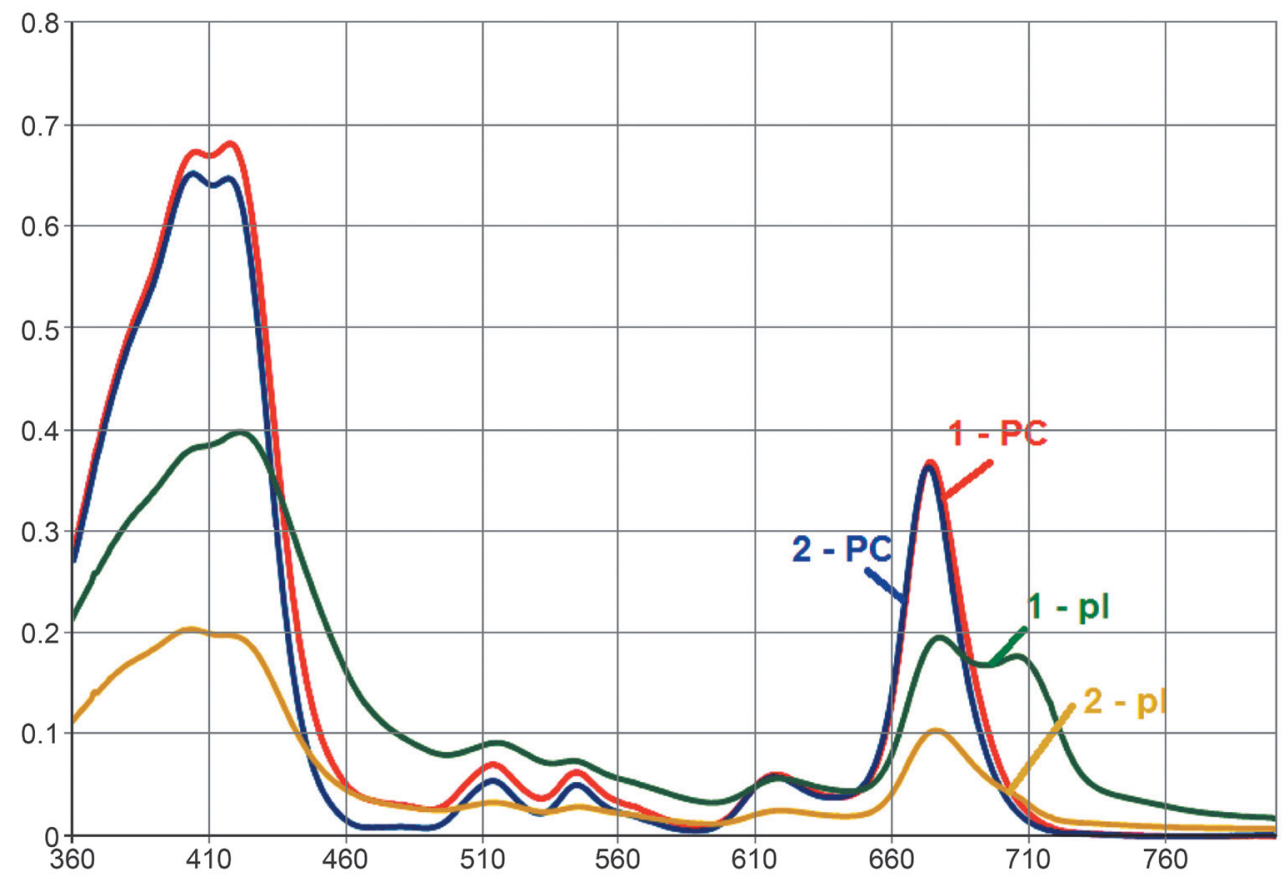

Figure 4. Absorbtion spectra of mixed micelles of conjugates with PC or pluronic F68 in PBS. 


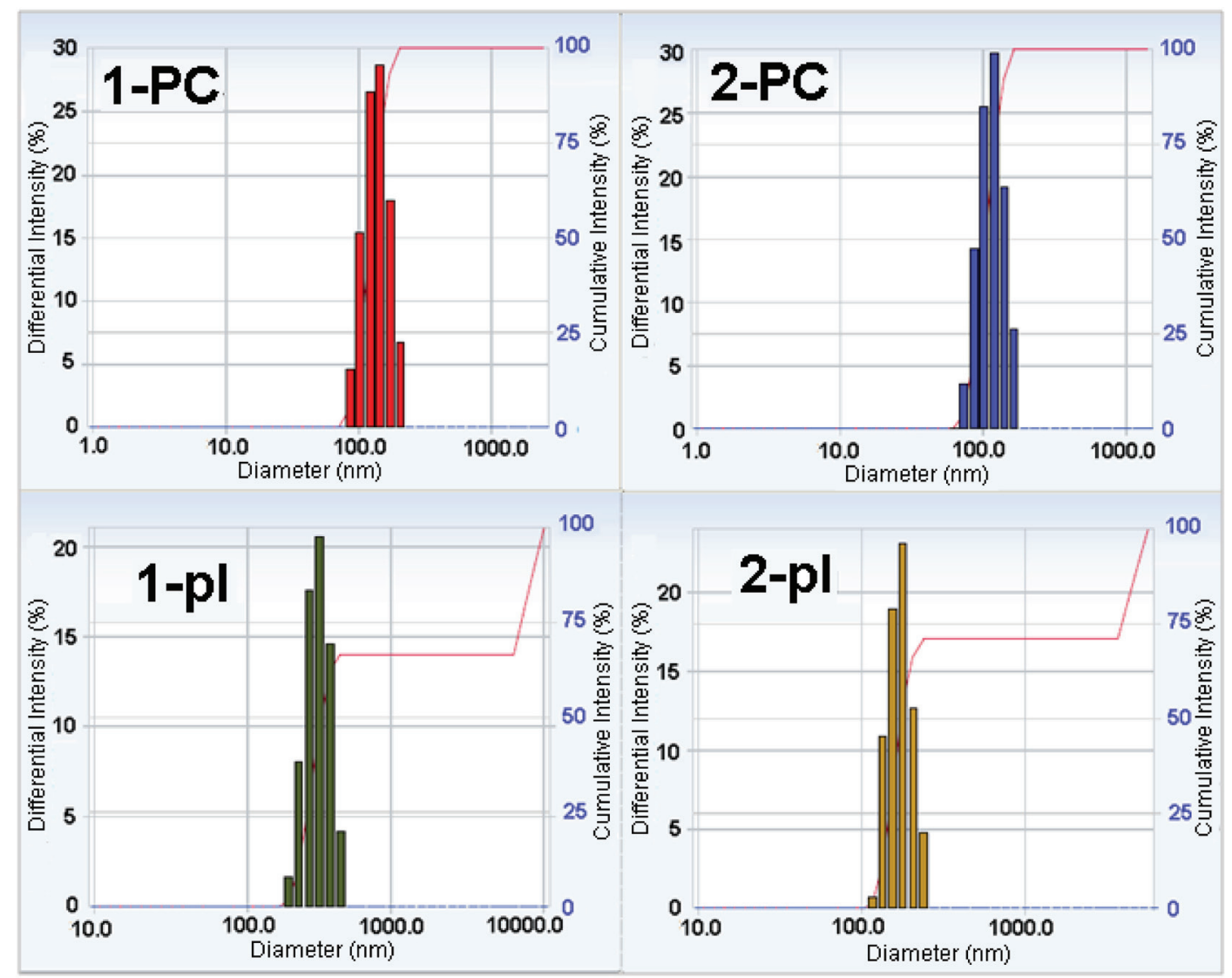

Figure 5. Particle size distribution for mixed micelles measured by laser scattering; $\mathbf{1}$ - PC (average diameter - 123.3 nm); 2 - PC (average diameter - $108.1 \mathrm{~nm}) ; \mathbf{1}$ - pl (average diameter - $621.3 \mathrm{~nm}) ; \mathbf{2}$ - $\mathbf{p l}$ (average diameter - $385.7 \mathrm{~nm}$ ).

structures. $^{[24,25]}$ The related spectra $\mathbf{1}-\mathbf{p l}$ and $\mathbf{2}-\mathbf{p l}$ at a ratio conjugate/pluronic 1:10 were resemble to those presented in Figure 4, but displayed certain turbidity and poor resolution. In comparison with conjugate - PC micelles, conjugate - pluronic micelles were larger in size and less stable. The mean sizes of $\mathbf{1}-\mathbf{p l}$ and $\mathbf{2}-\mathbf{p l}$ micelles (with the mass ratio conjugate/pluronic 1:50) were $621.3 \mathrm{~nm}$ and $385.7 \mathrm{~nm}$, respectively; their absorption spectra displayed significant changes after $24 \mathrm{~h}$ of storage, and after 1 week of storage the presence of mixed micelles was undetectable.

Mixed micelles of conjugates $\mathbf{1}-$ PC, $\mathbf{2}-\mathbf{P C}, \mathbf{1}-\mathbf{p l}$, and $\mathbf{2}-\mathbf{p l}$ were evaluated for their interaction with prostate carcinoma LNCaP cells and hepatocarcinoma Hep G2 cells; the uptake and internalization of conjugates were dependent on their structure, nature of solubilizers and cells used (Figure 6).
LNCaP

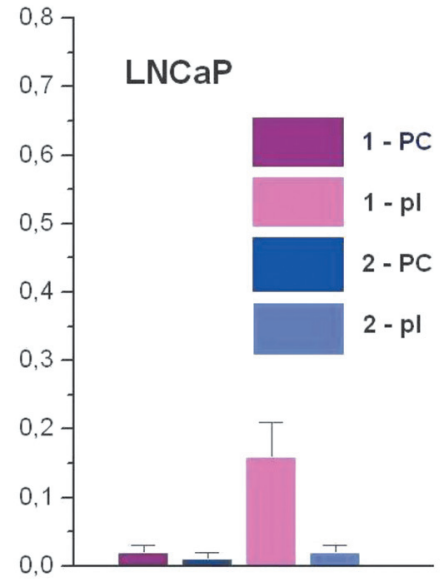

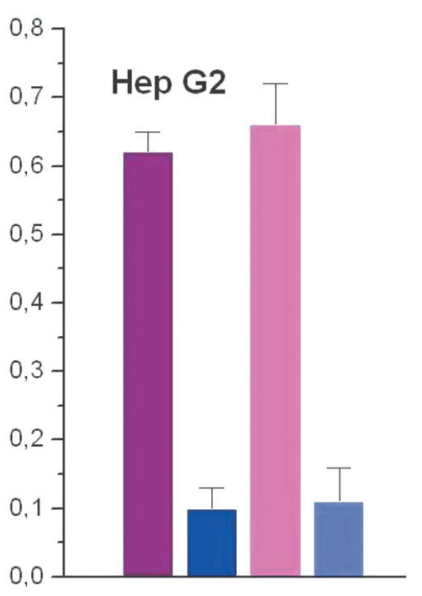

Figure 6. Uptake and internalization of conjugates by LNCaP and Hep G2 cells. 
The uptake of mixed micelles of conjugates $\mathbf{1}-\mathbf{P C}$, and $\mathbf{1}$ - pl by Hep G2 cells was incomparably stronger than those by LNCaP cells; in HepG2 cells conjugate 1 internalized about 5 -fold better than conjugate $\mathbf{2}$ (if these conjugates were similarly solubilized by PC). The uptake of conjugates in LNCaP cells was low, except the mixed micelles conjugate $\mathbf{1}-\mathbf{p l}$.

The obtained results revealed that structural peculiarities of conjugates $\mathbf{1}$ and $\mathbf{2}$ affect their affinity to cells more importantly than method of solubilization. New trifunctional conjugates solubilized either with phosphatidyl choline, or with pluronic may be used as probes for fluorescent imaging of cultured cells, these studies are in progress in our team, and the results will be presented elsewhere.

Acknowledgments. This study was supported by State Academies of Sciences Fundamental Research Program for 2013-2020 years (for chemical synthesis and biological studies - № 051820140003 and №419292017; for molecular modeling and spectroscopic studies - №01201363818) and Ministry of Education and Science (the state order 4.1929.2017/4.6)

\section{References}

1. Zheng X., Morgan J., Pandey S.K., Chen Y., Tracy E., Baumann H., Missert J.R., Batt C., Jackson J., Bellnier D.A., Henderson B.W., Pandey R.K. J. Med. Chem. 2009, 52, 4306-4318.

2. Sibrian-Vazquez M., Jensen T.J., Fronczek F.R., Hammer R.P., Vicente M.G.H. Bioconjugate Chem. 2005, 16, 852-863.

3. Sibrian-Vazquez M., Jensen T.J., Vicente M.G.H. Org. Biomol. Chem. 2010, 8, 1160-1172.

4. Hargus J.A., Fronczek F.R., Vicente M.G.H., Smith K.M. Photochem. Photobiol. B 2007, 83, 1006-1015.

5. Jensen T.J., Vicente M.G.H., Luguya R., Norton J., Fronczek F.R., Smith K.M. J. Photochem. Photobiol., B 2010, 100, $100-111$.

6. Jinadasa R.G.W., Hu X., Vicente M.G.H., Smith K.M. J. Med. Chem. 2011, 54, 7464-7476.

7. Dmitriev R.I., Ropiak H.M., Ponomarev G.V., Yashunsky D.V., Papkovsky D.B. Bioconjugate Chem. 2011, 22, 2507-2518.
8. Zhylitskaya H.A., Zhabinskii V.N., Litvinovskaya R.P., Lettieri R., Monti D., Venanzi M., Khripach V.A., Drašar P. Steroids 2012, 77, 1169-75.

9. Koivukorpi J., Sievänen E., Kolehmainen E., Král V. Molecules 2007, 12, 13-24.

10. Sadler S., Persons K.S., Jones G.B., Ray R. Bioorg. Med. Chem. Lett. 2011, 21, 4638-41.

11. Zheng G., Li H., Zhang M., Lund-Katz S., Chance B., Glickson J.D. Bioconjugate Chem. 2002, 13, 392.

12. Khan E.H., Ali H., Tian H., Rousseau J., Tessier G., Shafiullaha van Lier J.E. Bioorg. Med. Chem. Lett. 2003, 13, 1287.

13. Nikolaeva I.A., Misharin A.Yu., Ponomarev G.V., Timofeev V.P., Tkachev Ya.V. Bioorg. Med. Chem. Lett. 2010, 20, 2872-2875.

14. Nikolaeva I.A., Morozova J.V., Zavialova M.G., Novikov R.A., Tkachev Y.V., Timofeev V.P., Misharin A.Y., Ponomarev G.V. Macroheterocycles 2010, 3, 150-6.

15. Ponomarev G.V., Solovieva M.N., Dugin N.O., Zavialova M.G., Mehtiev A.R., Misharin A.Y., Novikov R.A., Tkachev Y.V., Popenko V.I., Timofeev V.P. Bioorg. Med. Chem. 2013, 21, 5420-5427.

16. Dugin N.O., Zavialova M.G., Novikov R.A., Timofeev V.P., Misharin A.Y., Ponomarev G.V. Macroheterocycles 2012, 5, 150.

17. Zolottsev V.A., Zazulina O.V., Morozevich G.E., Zavialova M.G., Misharin A.Y., Novikov R.A., Timofeev V.P., Koifman O.I., Ponomarev G.V. Macroheterocycles 2017, 10, $77-80$.

18. The Open Babel Package, version 2.0.1, http://openbabel. sourceforge.net/.

19. Phillips J.C., Braun R., Wang W., Gumbart J., Tajkhorshid E., Villa E., Chipot C., Skeel R.D., Kale L., Schulten K. J. Comput. Chem. 2005, 26, 1781-1802.

20. Zoete V., Cuendet M.A., Grosdidier A., Michielin O. J. Comput. Chem. 2011, 32, 2359-68.

21. Humphrey W., Dalke A., Schulten K. J. Molec. Graphics 1996, 14, 33

22. Park H., Na K. Biomaterials 2013, 34, 6992-7000.

23. Smith P.K., Krohn R.I., Hermanson G.T., Mallia A.K., Gartner F.H., Provenzano M.D., Fujimoto E.K., Goeke N.M., Olson B.J., Klenk D.C. Anal. Biochem. 1985, 150, 76-85.

24. Tamiaki H., Michitsuji T., Shibata R. Photochem. Photobiol. Sci. 2008, 7, 1225-1230.

25. Tamiaki H., Fukai K., Shimazu H., Nishide K., Shibata Y., Itoh S., Kunieda M. Photochem. Photobiol. Sci. 2008, 7, 1231-1237. 